antihypertensive drug (69\%) use were similar across ethnic subgroups (all p>0.2) After a mean follow-up of 95 months, eight patients (9\%) had died, six $(7 \%)$ received renal replacement therapy and five (6\%) had developed CKD. Five and ten years patient survival was similar for Asian and Caucasian patients (95\%) and poorest in Aborigines ( $81 \%$ and $70 \%)(p=0.016)$ with no impact of gender, ISN class, full house IF findings or PCR $>300$. Renal 5 and 10 year survival (endpoint RRT) was $100 \%$ for Asian, $100 \%$ and $96 \%$ for Caucasian vs $86 \%$ and $64 \%$ for Aborigines $(p=0.02)$. PCR $>350$ predicted worse renal survival $(p=0.03)$, which was not influenced by gender, increased baseline creatinine, ISN class, A/AC/C subclass or presence of full house IF deposits.

Conclusions: Asian patients have similar clinical and histological LN findings and experience equally good renal and patient outcomes as Caucasian patients in Western Australia, where the incidence rate of $L N$ is comparable with Europe. Whether the grim outlook for Aboriginal patients relates to intrinsic differences in LN pathophysiology and/or socioeconomic circumstances deserves further study. Acknowledgements: Supported by an unrestricted grant from the Arthritis Foundation of Western Australia. We acknowledge the contributions to data collection made by Drs Brandon Wong and Kimberly Minats

Disclosure of Interest: None declared

DOI: 10.1136/annrheumdis-2018-eular.2567

\section{AB0587 HAEMATOLOGICAL ALTERATIONS IN COLOMBIAN PATIENTS WITH SYSTEMIC LUPUS ERYTHEMATOUS}

J. Sanchez-Bautista ${ }^{1}$, Y. Santamaria-Alza ${ }^{2}$, A. Coy-Quiroga ${ }^{2}$, M. Alarcon-Gomez ${ }^{2}$, J. Fajardo-Rivero ${ }^{2}$, C. Figueroa-Pineda ${ }^{2}$, on behalf of Internal medicine department, Industrial University of Santander, Colombia. ' Johns Hopkins University, Baltimore, USA; ${ }^{2}$ Internal medicine, Universidad Industrial de Santander, Bucaramanga, Colombia

Background: Systemic Lupus Erythematosus (SLE) is an autoimmune disease, with multiple organs and system involvement. The most usual haematologica findings are anaemia, leukopenia, and thrombocytopenia. The prevalence of SLE in Colombia was 8.77 per 10000 persons between 2012 and 2016[.

Objectives: To evaluate the haematological alterations in a cohort of patients with SLE in Bucaramanga, Colombia.

Methods: A retrospective cohort study of 149 patients diagnosed with SLE according to the Systemic Lupus International Collaborating Clinics (SLICC) criteria. Descriptive analysis with frequencies, measures of central tendency and dispersion was done using Stata 12.0 software. The primary outcome was the presence of cytopenia, the secondary outcomes were anaemia, leukopenia, and thrombocytopenia. In the group comparison analysis, a chi-square test was used for qualitative variables and Wilcoxon or $T$ student test for quantitative variables according to their distribution. Bivariate analysis using logistic regression with OR measurement, $p$-value, and confidence intervals was performed.

Results: $82.5 \%$ were women, average age was 36.8 years. The primary outcome was found in the $79.8 \%$, anaemia in the $76.5 \%$, thrombocytopenia in the $22.1 \%$ and leukopenia in the $18.7 \%$. In group comparison analysis (cytopenia vs no cytopenia) a statistical difference was found in the variables sex $(p=0.023)$, skin involvement $(p=0.003)$, acute pneumopathy $(p=0.050)$, activity of the disease measured by the ECLAM scale $(p=0.037)$ and anti-DNA antibody titers $(p=0.032)$ In the bivariate analysis, there was an increased risk of cytopenias with statistica significance in male patients (OR: 3.82), ECLAM score greater than 5(OR: 4.75) and strongly positive anti-DNA antibodies (OR: 3.97). Regarding leukopenia there was an association with antiphospholipid syndrome (OR: 2.75), ECLAM greater than 5 (OR: 2.51), SLEDAI MEX greater than 10 (OR: 2.35) and strongly positive anti-DNA antibodies (OR: 2.36). Likewise, an increased risk of mortality was found in patients with leukopenia (OR: 3.92). In the case of thrombocytopenia, an association was found with a pericardial alteration (OR: 2.46), ECLAM greater than 5 points (OR: 3.65), SLEDAI MEX greater than 10 points (OR 2.42). An association with mortality was also observed (OR: 2.97). The risk of presenting anaemia was increased with the variables man (OR: 4.4), ECLAM greater than 5 points (OR: 3.14) and strongly positive anti-DNA antibodies (OR: 3.25).

Conclusions: This is the first Colombian study that evaluates haematological alterations in patients with SLE. The most frequent cytopenia was anaemia. It is possible to identify variables that can predict the appearance of cytopenia, such as the increase in the activity of the disease, which is susceptible to intervention. It is noteworthy that both leukopenia and thrombocytopenia are markers of mortality in patients with SLE.

\section{REFERENCE:}

[1] Fernandez-Avila D, Rincon-Riaño, D (2017) Prevalencia y caractersiticas demograficas del lupus eritematoso sistemico en Colombia, segun informacion del sistema integral de informacion de la proteccion social. Abstrac presentation. Bogotá, Colombia.
Acknowledgements: This research received no specific grant from any funding agency in the public, commercial, or not-for-profit sectors

Disclosure of Interest: None declared

DOI: 10.1136/annrheumdis-2018-eular.7291

\section{AB0588 IDENTIFICATION OF RISK FACTORS FOR HERPES VIRUS INFECTIONS WITH IMMUNOPHENOTYPING DURING INDUCTION THERAPY IN PATIENTS WITH ACTIVE LUPUS NEPHRITIS}

J. Kikuchi ${ }^{1}$, M. Ushikubo ${ }^{2}$, S. Saito ${ }^{1}$, H. Yasuoka ${ }^{1}$, K. Yamaoka ${ }^{1}$, H. Tsujimoto ${ }^{3}$, K. Sugahara ${ }^{3}$, T. Takeuchi ${ }^{1}{ }^{1}$ Division Of Rheumatology, Department Of Internal Medicine, Keio University School of Medicine; ${ }^{2}$ Department of Connective tissue disease, National Hospital Organization Tokyo Medical Center, Tokyo; ${ }^{3}$ Research Unit/Immunology and Inflammation, Mitsubishi Tanabe Pharma Corporation, Kanagawa, Japan

Background: Herpes virus infections (HVIs) including cytomegalovirus infections $(\mathrm{CMVs})$ and herpes zoster $(\mathrm{HZ})$ remains as major complications during treatments with immunosuppressant (IS) in patients with autoimmune diseases. ${ }^{12}$ Previous reports have suggested the associations between virus infections and characteristics of T cells. ${ }^{34}$

Objectives: To elucidate the characteristics of peripheral immune cells associated with risk factors of HVIs during induction therapies in patients with active lupus nephritis (LN)

Methods: Standardised peripheral immunophenotyping was performed using flow cytometry in active $L N$ and ANCA-associated vasculitis (AAV) patients starting induction therapy and also with inactive $L N$ patients with maintenance therapy between April 2015 to April 2017. The definition of HVIs was the infection necessary to administer anti-viral agents.

Results: Sixty-two LN patients and 11 AAV patients were enrolled. Among 30 active LN patients, 27 were analysed except for 3 patients ( 2 died and 1 withdrawn consent). Mean age was 41.7 years, 9 patients (33\%) had newly-onset, and mean SLE disease activity index (SLEDAI) was 19.3. All active LN patients were treated with prednisolone (PSL) (mean $51.7 \mathrm{mg} /$ day) and 25 were treated with an additional IS (cyclophosphamide [CYC];13, mycophenolate mofetil;8, tacrolimus;3, rituximab [RTX];1). Six (22.2\%) patients developed HVIs (5 CMVs and $1 \mathrm{HZ}$ ) within 3 months following induction therapy. None of the $32 \mathrm{LN}$ patients in maintenance phase (mean age, 54.8; SLEDAI, 2.5; PSL $2.5 \mathrm{mg} /$ day) developed HVls during the mean 2.8 years-observational period. Two (18.2\%) AAV patients developed HVIs within 3 months following induction therapy. All AAV patients (mean age, 64.3) were treated with PSL (mean $41.8 \mathrm{mg} /$ day) and 10 with IS (CYC;5, RTX;3 azathioprine; 1 , methotrexate; 1 .

Among active LN patients, univariate analysis revealed that older age, lower proportions of naïve CD8 $+\mathrm{T}$ cells, higher proportions of effector CD8 $+\mathrm{T}$ cells and HLA-DR +regulatory T cells (Tregs) at baseline and lower naïve CD8 +T cells at month 3 associated with HVIs $(p=0.011, p<0.001, p=0.009, p=0.024, p<0.001$ respectively). Unexpectedly, lymphocyte count, IgG titer, usage of CYC at baseline, renal response and change in SLEDAI at month 3 did not associate with $\mathrm{HVIs}$. Multivariate analysis revealed that low proportions of naïve CD $8+T$ cells and high proportions of HLA-DR +Tregs at baseline were the only detectable independent risk factor for HVIs $(\mathrm{p}=0.014)$

Among AAV patients, univariate analysis showed that older age, lower propor tions of naïve CD8 $+\mathrm{T}$ cells, higher proportions of Tregs at baseline associated with HVIs. However, multivariate analysis showed no independent risk factor for HVIs among them.

Conclusions: Our results suggest that active LN patients with low proportion of naïve CD8 + T cells and high HLA-DR +Tregs at the time of induction therapy should be closely monitored for HVIs. The different results between LN and AAV implicated the different risks of HVIs by immunophenotyping. Larger prospective study is desired to confirm our results.

\section{REFERENCES}

[1] Takizawa Y. et al. Rheumatology (Oxford). 2008;47:1373-8.

[2] Chakravarty EF, et al. Lupus. 2013;22:238-44

[3] Weltevrede M, et al. Exp Gerontol. 2016;77:87-95.

[4] Egli A, et al. PLoS One. 2012;7:e43937.

Disclosure of Interest: J. Kikuchi: None declared, M. Ushikubo: None declared, S Saito: None declared, H. Yasuoka: None declared, K Yamaoka: None declared, H. Tsujimoto Employee of: Mitsubishi Tanabe Pharma Corporation, K Sugahara Employee of: Mitsubishi Tanabe Pharma Corporation, T. Takeuch Grant/research support from: Mitsubishi Tanabe Pharma Corporation DOI: 10.1136/annrheumdis-2018-eular 5202 


\section{AB0589 RELEVANCE OF B AND T CELL SUBSETS TO LUPUS FLARE IN KOREAN PATIENTS WITH SYSTEMIC LUPUS ERYTHEMATOSUS}

J.H. Koh ${ }^{1}$, N. Lee ${ }^{2}$, W.-U. Kim ${ }^{3} .{ }^{1}$ Division of Rheumatology, Department of Internal Medicine, Pusan National University Hospital, Pusan; ${ }^{2}$ Center for Integrative Rheumatoid Transcriptomics and Dynamics, The Catholic University of Korea; ${ }^{3}$ Division of Rheumatology, Department of Internal Medicine, Seoul St. Mary's hospital, the Catholic university of Korea, Seoul, Korea, Republic of Ireland

Background: Systemic lupus erythematosus (SLE) is a systemic autoimmune disease with heterogeneous clinical manifestations and is characterised with autoreactive $T$ cells and autoantibody overproduction by activated $B$ cells.

Objectives: The aims of this study were to characterised T-cell and B-cell subpopulation phenotype in Korean patients with SLE, and to elucidate the association between lymphocyte subpopulation and lupus activity.

Methods: We used multicolor flow cytometry to analyse subsets of peripheral blood B-cells (defined by CD19, IgD, CD27, and CD38) and T-cells (CD3, CD4, CD8, CD45RA, CCR7) in 26 patients with SLE and 22 age- and sex-matched healthy subjects. Baseline and 6 month follow-up SLE disease activity index (SLEDAI) was recorded, and SLEDAI score $>6$ was considered as lupus flare-up. Lymphocyte phenotype was also compared between stable disease and lupus flare-up.

Results: The number of $B$ cells and CD8 $+T$ cells were not different between SLE patients and healthy subjects; however, non-switched memory (NSwM) B cells was decreased in SLE patients. Double negative (DN) T cells, CD4 +T cells and its subset [naïve, central memory (CM), effector memory (EM) and terminally differentiated effector memory (TEMRA) cells] were decreased in SLE patients compared to healthy controls. Patients with lupus flare-up showed significantly decreased CD4 +and DN T cells, whereas CD4 +EM T cells were increased in patients with lupus flare up, compared to stable SLE. SLEDAI was correlated with DN T cells $(\rho=-0.728, p<0.001)$, CD $4+$ CM T cells $(\rho=-0.544, p=0.004), C D 4$ + EM T cells $(\rho=-0.697, p<0.001)$ and CD $8+E M$ T cells $(\rho=-0.408, p=0.039)$. Six (23\%) patients experienced lupus flare and a patient presented still high disease activity at 6 month follow-up visit. Interestingly, these patients showed the low number of DN T cells, CD4 +EM and TEMRA cells at baseline when they were stable.

Conclusions: Biassed differentiation of T-cells was associated with lupus flare and aggravation of SLE 6 months later. Understanding T cell subset enables accurate stratification of lupus flare-up and personalised approach.

\section{REFERENCES:}

[1] Nakayamada S, Iwata S, Tanaka Y. Relevance of lymphocyte subsets to B cell-targeted therapy in systemic lupus erythematosus. Int $\mathrm{J}$ Rheum Dis 2015;18:208-218.

[2] Anolik JH, Barnard J, Owen T, Zheng B, Kemshetti S, Looney RJ, et al. Delayed memory $B$ cell recovery in peripheral blood and lymphoid tissue in systemic lupus erythematosus after B cell depletion therapy. Arthritis Rheum 2007;56:3044-3056.

[3] Tsokos, G. C., M. S. Lo, P. C. Reis, and K. E. Sullivan. 2016. New insights into the immunopathogenesis of systemic lupus erythematosus. Nat Rev Rheumatol 12: 716-730.

Acknowledgements: We wish to thank Jihoon Kwon, the M.S. student for his excellent support.

Disclosure of Interest: None declared

DOI: 10.1136/annrheumdis-2018-eular.7514

\section{AB0590 A VALIDATION STUDY OF THE PREGNANCY MORBIDITY QUESTIONNAIRE(PMQ) IN WOMEN WITH ANTIPHOSPHOLIPID ANTIBODIES AND PREGNANCY MORBIDITY}

K. Schreiber ${ }^{1,2}$, S. Koder ${ }^{3}$, C. Ay ${ }^{3}$, I. Pabinger ${ }^{3}$, S. Jacobsen ${ }^{2}{ }^{1}$ Department of Thrombosis and Haemophilia, Guy's and St Thomas' Hospital, London, UK; ${ }^{2}$ Copenhagen Lupus and Vasculitis Clinic, Center for Rheumatology and Spine Diseases, Copenhagen University Hospital, Copenhagen, Denmark, ${ }^{3}$ Clinical Division of Haematology and Haemostaseology, Department of Medicine I, Medical University of Vienna, Vienna, Austria

Background: The presence of antiphospholipid antibodies (aPL) are associated with pregnancy complications. There is a lack of validated pregnancy questionnaires to assess previous pregnancy morbidity reliably in aPL positive patients. We therefore designed the pregnancy morbidity questionnaire (PMQ). Objectives: To validate the pregnancy morbidity questionnaire (PMQ) in the prospective Vienna Lupus Anticoagulant and Thrombosis Study (LATS) cohort. Methods: The Vienna Lupus Anticoagulant and Thrombosis Study (LATS) is an ongoing, single-centre, biobank-based, prospective observational cohort study enrolling patients (age $>18$ years) who are persistently positive for lupus anticoagulant (LA) (two positive tests at least 12 weeks apart) with or without a history of thrombosis or pregnancy complications ${ }^{1}$. The cohort currently consists of 150 patients (mean age: 41.3 years, female gender: $n=122(81.3 \%)$, history of thrombosis or pregnancy complications: $\mathrm{n}=111(74.0 \%))$. Of these 150 women, 15 were approached at their follow up visit and invited to fill out the PMQ. The PMQ consists eight questions outlined in table 2 .

Results: Twelve women agreed to participate, of whom nine had a previous history of pregnancy and/or pregnancy complications. Patient characteristics are shown in table 2. PMQ results are outlined in table 2.

Abstract AB0590 - Table 1

\begin{tabular}{|lc|}
\hline \multicolumn{2}{|c|}{ Patient Characteristics (N=9) } \\
\hline $\begin{array}{l}\text { Age at the time of questionnaire, mean (SD, range) } \\
\text { Years since last pregnancy, mean (SD, range) } \\
\text { Lupus anticoagulant positive only } \\
\text { Antiphospholipid syndrome }\end{array}$ & $58(+/-13.6,25-86)$ \\
\multicolumn{1}{|c|}{ Pregnancies (N=20) } & $35(+/-10,20-58)$ \\
& $5(25 \%)$ \\
\hline $\begin{array}{l}\text { Maternal age at pregnancy, mean (SD, range) } \\
\text { Live-birth rate }\end{array}$ & $2(10 \%)$ \\
Gestational age, weeks (SD, range) & $24.5(+/-4.3,18-33)$ \\
Birthweight, kg (SD, range) & $17 / 20(85 \%)$ \\
aPL related early pregnany loss (<10 weeks) & $34.8(+/-11,<10-24)$ \\
aPL related preterm delivery (<34 weeks) & $3.2(+/-0.5,2.2-4)$ \\
aPL related preterm delivery due to placental insufficiency & $2(10 \%)$ \\
Aspirin taken during pregnancy & $1(5 \%)$ \\
Heparin taken during pregnancy & $1(5 \%)$ \\
\hline Key: SD, standard deviation & $0(0 \%)$ \\
\hline
\end{tabular}

Abstract AB0590 - Table 2. Pregnancy questionnaire results

\begin{tabular}{lccc}
\hline & $\begin{array}{c}\text { Correct answer, } \\
\text { validated against cohort } \\
\text { info }\end{array}$ & $\begin{array}{c}\text { Detailed answer, but not } \\
\text { captured on cohort entry }\end{array}$ & $\begin{array}{c}\text { Incorrect } \\
\text { answer }\end{array}$ \\
\hline $\begin{array}{l}\text { Q1: Pregnancy date } \\
\text { Q2: Live birth }\end{array}$ & $20(100 \%)$ & $0 \%$ & $0 \%$ \\
$\begin{array}{l}\text { Q3: Gestational age at } \\
\text { delivery }\end{array}$ & $9(100 \%)$ & $0 \%$ & $0 \%$ \\
$\begin{array}{l}\text { Q4: Weight at delivery } \\
\text { Q5: aPL related }\end{array}$ & $1(45 \%)$ & $11(55 \%)$ & $0 \%$ \\
pregnancy & $18(90 \%)$ & $19(95 \%)$ & $0 \%$ \\
$\begin{array}{l}\text { complications } \\
\text { Q6: Aspirin during }\end{array}$ & $20(100 \%)$ & $0 \%$ & $2(10 \%)$ \\
$\begin{array}{l}\text { pregnancy } \\
\text { Q7: Heparin during } \\
\text { pregnancy }\end{array}$ & $20(100 \%)$ & $0 \%$ & $0 \%$ \\
$\begin{array}{l}\text { Q8: Other medications } \\
\text { during pregnancy }\end{array}$ & $20(100 \%)$ & $0 \%$ & $0 \%$ \\
\hline
\end{tabular}

Conclusions: Our aim was to validate the PMQ in the prospective Vienna Lupus Anticoagulant and Thrombosis Study (LATS) cohort. Patients were able to recall their pregnancy history in great detail over a period of more than three decades. Our PMQ may provide a tool to assess previous pregnancy morbidity in patients with antiphospholipid antibodies.

\section{REFERENCES:}

[1] Gebhart, J. P., F.; Koder, S.; Perkmann, T.; Quehenberger, P.; Zoghlami, C.; Ay, C.; Pabinger, I. Increased mortality in patients with the lupus anticoagulant: the Vienna Lupus Anticoagulant and Thrombosis Study (LATS). Blood 125, 3477-3483. http://dx.doi.org/10.1182/blood-2014-11-611129 (2015).

Disclosure of Interest: None declared DOI: 10.1136/annrheumdis-2018-eular.5791 